\title{
Phyto-fabrication, characteristics and anti- candidal effects of silver nanoparticles from leaves of Ziziphus mauritiana Lam
}

Rusol M. Al-Bahrani', Sura Muayad Abdel Majeed', Mustafa Nadhim Owaid2,3,", Abdullah B. Mohammed ${ }^{1}$, Duha A. Rheem ${ }^{1}$

1 Department of Biology, College of Science, University of Baghdad, Jadriya, Baghdad 10071, Iraq 2 Department of Heet Education, General Directorate of Education in Anbar, Ministry of Education, Hit, Anbar 31007, Iraq 3Department of Ecology, College of Applied Sciences, University of Anbar, Hit, Anbar 31007, Iraq.

\section{ABSTRACT}

In this work, silver nanoparticles (AgNPs) were biosynthesized from leaves of Ziziphus mauritiana Lam. jujube plant in Iraq and tested against fungal pathogens. Extract of leaves of $Z$. mauritiana mixed with $10^{-3} \mathrm{M} \mathrm{AgNO}_{3}$ exposed to slight sunlight for 3 days. Characterization of AgNPs was done using UV-visible spectroscopy, SPM (scanning probe microscopy) and atomic force microscopy (AFM). The change of solution color from pale brown to dark brown and the exhibited maximum peak at $445 \mathrm{~nm}$ accepted as an indicator to biosynthesized AgNPs. Aqueous extract of Ziziphus mauritiana is considered as biological reduced and stabilized agent for $\mathrm{Ag}^{+}$to $\mathrm{Ag}^{\mathrm{o}}$. AFM showed the formation of irregular shapes of AgNPs. The biosynthesized silver nanoparticles have an average of diameter of 67.19. The biosynthesized AgNPs from $Z$. mauritiana leaves were tested as nano-drugs against four human pathogenic fungi. The highest concentration 100\% of AgNPs has 25 $\mathrm{mm}$ inhibition zone against Candida krusei. These nanoparticles were found to be useful to reduce Candidiasis.

Keywords: Pharmaceutical, AgNPs, Candida sp., green nanotechnology, Jujube, biosynthesis.

\section{INTRODUCTION}

Nanoparticles are the most fundamental component in the fabrication of nanostructures. A nanoparticle is bigger than an atom or a simple molecule that is governed by quantum mechanics ${ }^{1}$. Currently, most of applications of silver nanoparticles are antibacterial and antifungal agents, anticancer nano-drugs ${ }^{2}$ and in the drug delivery ${ }^{3}$. The biosynthesis is considered of the best ways to reduce 
metal ions to atoms and produce nanoparticles which are prepared by the safe and eco-friendly way using microorganisms and extracts of the plant ${ }^{4}$. Recently, many plants were used to synthesize potent AgNPs from Cassia fistula fruit ${ }^{5}$, Bryophyllum pinnatum leaf extract ${ }^{6}$ and Limonia acidissima L. leaf ${ }^{7}$ against various fungal and bacterial species.

Few recent studies, started in 2014, were achieved to synthesize silver and gold nanoparticles using barks, and fruits of Ziziphus spp. and tested against some human pathogenic bacteria ${ }^{8-10}$. While Divband et al. ${ }^{11}$ used the produced nanoparticles from $Z$. spina christi fly ash to remove Lead $\left(\mathrm{Pb}^{+2}\right)$ from aqueous solutions. In contrast, many studies were achieved in vitro to test bioactivity of crude extracts of this plant against bacteria, molds, and yeasts. Also, Alcoholic and aqueous extracts of the leaves showed the highest inhibition activity toward Candida albicans $^{12}$ compared with bacterial strains ${ }^{13}$ because Ziziphus plant leaves have many biologically active compounds like phenols, saponins, and alkaloids ${ }^{14}$. Furthermore, saponin extract of $Z$. spina-christi has clear antibacterial activity ${ }^{15}$. Leaves of Ziziphus sp. has an antimicrobial effect ${ }^{12,13,15}$, thus it was used in the treatment of wounds, diarrhea, and gonorrhea ${ }^{16}$.

Jujube, Ziziphus mauritiana, is distributing in western and southern Iraq under dry conditions ${ }^{17}$. The genus Ziziphus sp. belongs to the evergreen herbal plants and to Rhamnaceae family ${ }^{18}$. Generally, many recent studies investigated antifungal activity of Ag-NPs against Candida sp., dermatophytic and plant pathogenic fungi ${ }^{19}$. From literatures, no tests against yeast infections were applied or studied by silver or gold nanoparticles of Ziziphus spp. This work is considering the first achievement for using the biosynthesis eco-friendly silver nanoparticles from Ziziphus mauritiana Jujube plant in the treatment of Candidiasis (yeasts infections) in vitro.

\section{METHODOLOGY}

\section{Fungal Isolates}

Four Candida species, C. krusei, C. zeylanoides, C. albicans and C. guillermondii, were obtained from Central Public Health Laboratory, Medical City Hospital, Baghdad, Iraq, which were isolated from mouths of patients. These isolates were maintained using Sabroud Dextrose Agar and used to detect bioactivity test of silver nanoparticles synthesized from Ziziphus mauritiana Lam. Leaves toward the fungal pathogens.

\section{Preparing aqueous extract of Ziziphus mauritiana Lam. leaves}

Leaves of $Z$. mauritiana Lam. were collected from its tree in Baghdad, washed with distilled water, dried at room temperature at $25 \pm 2{ }^{\circ} \mathrm{C}$, and grinded by the blender. About $200 \mathrm{~g}$ of the powder was put in a clean glass bottle, added 2 liters of distilled water 1:10 (w/v), and heated for 1 hour at $60^{\circ} \mathrm{C}$. After the cooling, the aqueous extract was filtered using Whatman No. 1 filter paper. This solution was considered as a crude extract solution and stored at $2{ }^{\circ} \mathrm{C}$ until use.

\section{Green synthesis and Characteristics of Ag nanoparticles}

The required weight of $\mathrm{AgNO}_{3}$ was dissolved in D.W. and then $5 \mathrm{ml}$ of $10^{-3} \mathrm{M}$ $\mathrm{AgNO}_{3}$ solution was mixed with $45 \mathrm{ml}$ of aqueous extract of $Z$. mauritiana leaves and put in $250 \mathrm{ml}$-volumetric flask. In another flask $5 \mathrm{ml} \mathrm{D.W}$. was added to $45 \mathrm{ml}$ of the aqueous extract as control. The two flasks exposed to slight sunlight at $26 \pm 2$ ${ }^{\circ} \mathrm{C}$ for 3 days. When putting $\mathrm{AgNO}_{3}$ solution with aqueous extract of $\mathrm{Z}$. mauritiana leaves, the changing in color was observed that indicated formation of AgNPs. Characterization of AgNPs was done using UV-visible spectroscopy, SPM (scanning probe microscopy) and AFM (atomic force electron microscopy).

\section{Anti-candidal activity of AgNPs}

Silver Nanoparticles were applied against fungi by determination zone of inhibition in vitro. Anti-fungal activity of the biosynthesized AgNPs was investigated against some Candida species (C. krusei, C. zeylanoides, C. albicans and C. guillermondii) by well diffusion method using Sabouraud Dextrose Agar (SDA). The density of the yeast inoculum was adjusted to $105 \mathrm{cfu} / \mathrm{ml}$. One hundred microliters $(100 \mu \mathrm{l})$ of the yeast inoculum was added on SDA medium and spread using a sterile cotton swab even distribution of the inoculum. A sterile cork was used to make $9 \mathrm{~mm}$ wells into the plate, added AgNPs solution and left at cooling place for $30 \mathrm{~min}$ to allow absorption of excess fluid. Of AgNPs concentrations 25, 50, 75 and $100 \%$, only $50 \mu$ per well were poured into the wells of the plate. The control well was studied with $50 \mu \mathrm{l} /$ well crude sample in each concentration $(25,50,75$ and 100\%) for comparison purpose. These Petri dishes were then incubated at 35 ${ }^{\circ} \mathrm{C}$ for 18 hours and examined for measuring zone of inhibition.

\section{RESULTS AND DISCUSSION}

\section{Characterization of silver nanoparticles}

The changing color of the mix (aqueous extract plus $\mathrm{AgNO}_{3}$ solution) takes place from pale brown to dark brown color, while no color change is observed in the aqueous extract without $\mathrm{AgNO}_{3}$ solution because of the role of $\mathrm{Z}$. mauritiana Lam. leaves extract in the mix as a reductant and stabilizer agent. The change in color from pale brown to dark brown indicates biosynthesis of AgNPs as mentioned by Kredy15. The formation of AgNPs by using $Z$. mauritiana Lam. leaves extract is confirmed by UV-Vis spectroscopy after $27 \mathrm{hr}$ under slight sunlight at $26 \pm 2{ }^{\circ} \mathrm{C}$. The highest UV-visible peak is $445 \mathrm{~nm}$ at absorption 0.925 that confirms the for- 
mation of silver nanoparticles due to excitation of surface plasmon vibrations in silver nanoparticles. These results of color and UV-Vis spectrum agree with many recent studies for biosynthesis of AgNPs from plants and fungi extracts ${ }^{9,20}$.

Surface topography and size of the sample film were investigated using Granularity Cumulation distribution chart by scanning probe microscopy (SPM) and atomic force electron microscopy (AFM) images. Also, AFM images exhibited the histogram of the percentage of AgNPs as a function of the grain size as in Figure 1. The average particle size determined from SPM is approx. $67.19 \mathrm{~nm}$, and the diameters of $50 \mathrm{~nm}(\leq 10 \%), 65 \mathrm{~nm}(\leq 50 \%), 85 \mathrm{~nm}(\leq 90 \%)$ and $105 \mathrm{~nm}(\leq 2.3)$ as shown in Table 1 and Figure 1. The range of diameters is from 55 to $105 \mathrm{~nm}$ and this is an evidence for silver nanoparticles biosynthesis from $Z$. mauritiana leaf extract. AFM of the surface morphology of the film gives a good indicator for the formation of AgNPs. Of SPM imager surface roughness analysis (Figure 2), average of roughness is $51 \mathrm{~nm}$, core roughness depth is $176 \mathrm{~nm}$ and the reduced valley depth is $34 \mathrm{~nm}$. The surface topography of the AgNPs exhibited in Figures 2A (lateral view) and 2B (3D view) and it is clear that $\mathrm{Ag}$ nanoparticles are irregular in shape, having a cover of the organic shell ${ }^{21}$ and are aggregated as in table1. These results agree with preparations of gold nanoparticles (AuNPs) from extract of $Z$. mauritiana leaves with range from 20 to $40 \mathrm{~nm}^{22}$.

Table 1. Granularity Cumulation distribution, volume and average of diameters of AgNPs

\begin{tabular}{|c|c|c|c|c|c|c|c|c|c|c|c|}
\hline Diameter $(\mathrm{nm})<$ & 55 & 60 & 65 & 70 & 75 & 80 & 85 & 90 & 95 & 100 & 105 \\
\hline Volume $(\%)$ & 2.3 & 29.41 & 27.06 & 14.12 & 11.76 & 1.18 & 2.35 & 3.53 & 3.53 & 2.35 & 2.35 \\
\hline Cumulation (\%) & 2.35 & 31.76 & 58.82 & 72.94 & 84.71 & 85.88 & 88.24 & 91.76 & 95.29 & 97.65 & 100 \\
\hline
\end{tabular}

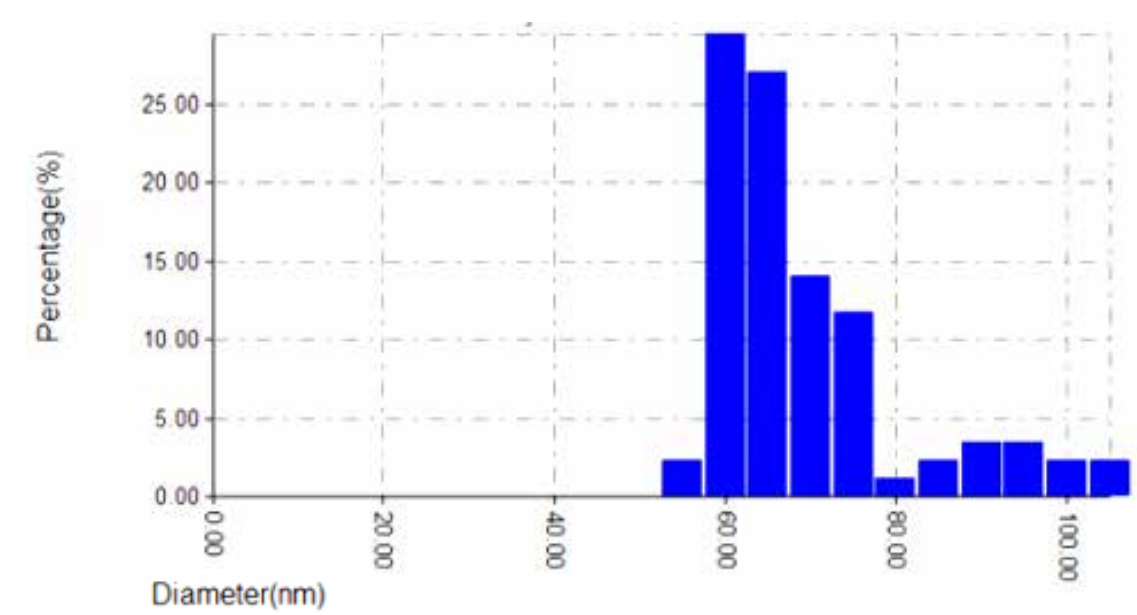

Figure 1. Histogram of particle size distribution of the biosynthesized silver nanoparticles
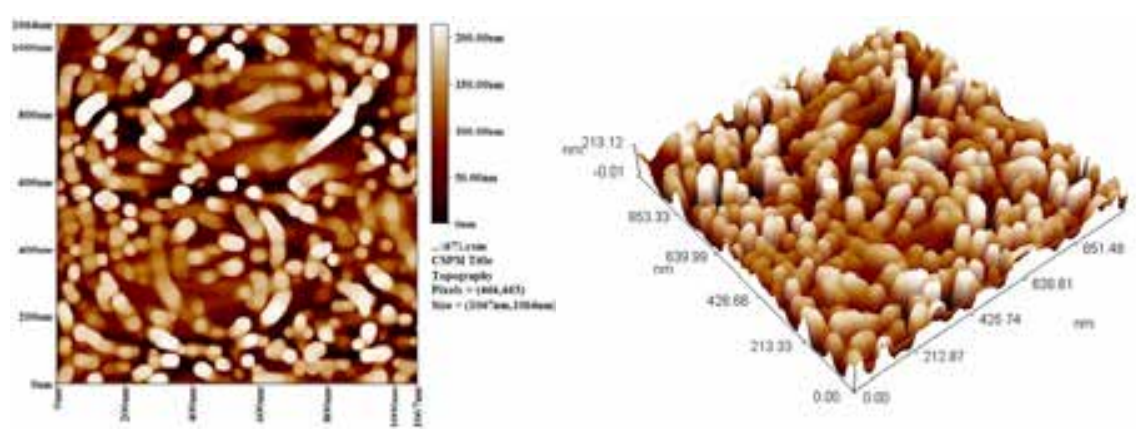

Figure 2. AFM of the biosynthesized silver nanoparticles

\section{Antifungal activity of the synthesized silver nanoparticles}

The biosynthesized AgNPs from Ziziphus mauritiana leaves were tested as a nano-drug against human pathogenic fungi which were isolated from patients' mouth in the Medical City Hospital in Baghdad. The possible anti-fungal activities of the biosynthesized AgNPs and the aqueous extract were examined toward four pathogenic fungi, Candida sp., (C. krusei, C. zeylanoides, C. albicans and C. guillermondii) on SDA medium by well diffusion method (Figures 3 and 4). The aqueous extract of $Z$. mauritiana at concentration of $100 \%$ showed a slight inhibitory effect toward some Candida species, while concentrations of 25\%, 50\%, 75\% were not exhibited any inhibitory effects except with the final two concentrations (57\% and 50\%) as shown in Figure 3. However, this figure showed the bioactivity of silver nanoparticles against Candida species is increasing with the increase of AgNPs concentrations. The higher inhibitory effect (zone of inhibition) is $25 \mathrm{~mm}$ against Candida krusei by the concentration 100\% of AgNPs compared with 20 $\mathrm{mm}$ by the plant extract alone (100\%), followed 24 and $18 \mathrm{~mm}$ by the same pathogen in case the concentrations $75 \%$ and $50 \%$ respectively. Furthermore, the lower concentration of $\mathrm{AgNO}_{3}$ (25\%) was inhibited C. krusei (12 mm) while the concentration of extract $25 \%$ did not have any inhibitory effect as shown in Figures 3B and 4. Generally, the concentrations of extract 25\%-75\% did not inhibit other species C. zeylanoides, C. albicans and C. guillermondii (Figure 3A). The zone of inhibition of AgNPs is $18 \mathrm{~mm}$ when using the concentrations 50\% and 100\% in case C. krusei and C. zeylanoides, respectively. From another hand, the zone of inhibition of C. albicans and C. guillermondii is $16 \mathrm{~mm}$ when using the dose $100 \%$ (AgNPs). While the lower inhibitory effect is reached $12 \mathrm{~mm}$ by the concentration $25 \%$ for all Candida species (Figure 3B). The results of the zone of inhibition in this study agree with biomedical applications of the biosynthesized AgNPs from this plant against pathogenic bacteria. 
Some researchers have reported that the positive charge on the silver ion is critical for its antibacterial and antifungal activities through the electrostatic attractions between the negative charge of the cell membrane of microbes and the positive charge of AgNPs ${ }^{23,24}$. Generally, AgNPs have a moderate inhibitory effect against Candida infections that agrees with results of zone of inhibition of AgNPs against Candida spp. by Owaid et al. ${ }^{25}$. The bioactivity of Ziziphus sp. leaves may be return to their antibacterial and antifungal effects in the crude form as mentioned by many studies ${ }^{12,13,15}$ especially toward Candida yeasts ${ }^{12}$ because Ziziphus plant leaves have phenols, saponins, and alkaloids ${ }^{14}$. Also, the role of these AgNPs are considered as antifungal agents, maybe return to the presence of plant bioorganic capping material upon the AgNPs which enables them to observe enhanced anticandidal activity ${ }^{26}$. All these results are agreeing with the recent works ${ }^{8,9,16,22}$ but this study is considered the first test to investigate activity of the biosynthesis AgNPs from leaves of Ziziphus mauritiana Lam. against native Candida spp.

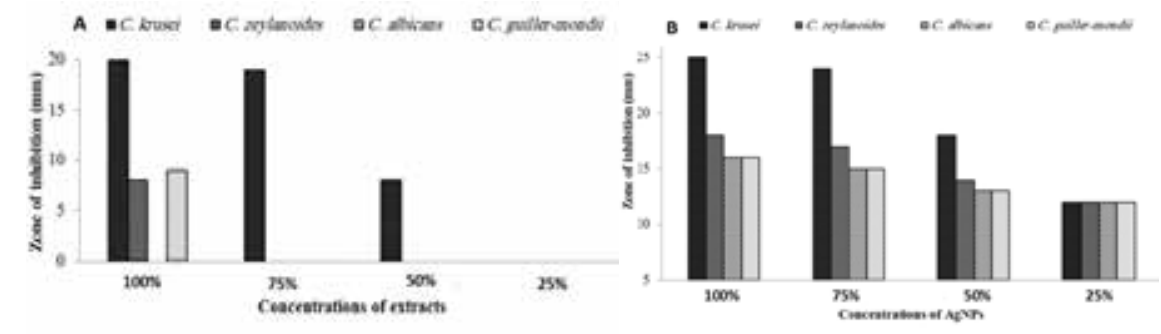

Figure 3. Zone of inhibition of aqueous extract of Jujube leaves (A) and its silver nanoparticles (B) against Candida species.

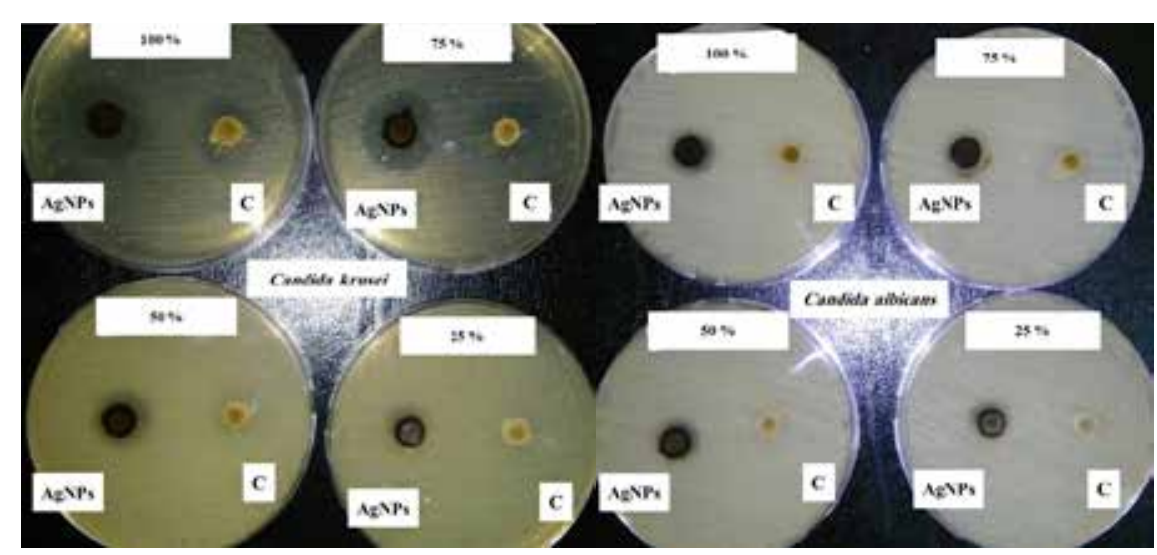

Figure 4. Zone of inhibition of Ag nanoparticles and aqueous extracts of Jujube (C) against Candida spp.

\section{CONCLUSION}

In this investigation, silver nanoparticles were synthesized in irregular shapes from leaves of Ziziphus mauritiana jujube tree in Iraq. The best absorption peak was located at $445 \mathrm{~nm}$ which established by using UV-Visible spectrum after change of color of the mix from pale brown to dark brown. The silver nanoparticles of $Z$. mauritiana leaves have average of diameter $67.19 \mathrm{~nm}$ with ranging from $55 \mathrm{~nm}$ to $105 \mathrm{~nm}$. The biosynthesized AgNPs were used as a nano-drug against human pathogenic fungi (Candida sp.) which were isolated from patients' mouth in the Medical City Hospital in Baghdad. The higher anticandidal activity showed against Candida krusei with zone of inhibition $25 \mathrm{~mm}$ in case AgNPs concentration $100 \%$ compared with zone of inhibition $20 \mathrm{~mm}$ by the plant extract alone (100\%), followed 24 and $18 \mathrm{~mm}$ by the same pathogen in case the concentrations of AgNPs 75\% and 50\% respectively. The lower sensitivity of AgNPs was $12 \mathrm{~mm}$ recorded for all Candida species at the concentration $25 \%$.

\section{ACKNOWLEDGEMENT}

The authors thank Department of Biology in University of Baghdad for achieving this work easily. Also, they are thanking Central Public Health Laboratory in Medical City Hospital, Baghdad for obtaining the human pathogenic fungi.

\section{REFERENCES}

1. W Al-Taa'y, MA Nabi, RM Yusop, E Yousif, BM Abdullah, J Salimon, N Salih and SI Zubairi. Effect of Nano ZnO on the Optical Properties of Poly(vinyl chloride) Films. Int. J. Polymer Sci. 2014, 697809.

2. T Muhsin and A Hachim. Antitumor and Antibacterial Efficacy of Mycofabricated Silver Nanoparticles by the Endophytic Fungus Papulaspora pallidula. American J. Bioeng. Biotech. 2016 2(1), 24-38.

3. WH De Jong and PJA Borm. Drug delivery and nanoparticles: Applications and hazards. Int. J. Nanomed. 20o8, 3, 133-149.

4. A Kusior, J Klich-Kafel, A Trenczek-Zajac, K Swierczek, M Radecka and K Zakrzewska. $\mathrm{TiO}_{2}-$ $\mathrm{SnO}_{2}$ Nanomaterials for Gas Sensing and Photocatalysis. J. Eur. Ceramic Soc. 2013, 33, 22852290 .

5. MI Rashid, LH Mujawa, MI Mujallid, M Shahid, ZA Rehan, MKI Khan and IMI Ismail. Potent bactericidal activity of silver nanoparticles synthesized from Cassia fistula fruit. Microbial Pathogenesis 2017, 107, 354-360.

6. FK Tareq, Mst Fayzunnesa and Md S Kabir. Antimicrobial activity of plant-median synthesized silver nanoparticles against food and agricultural pathogens. Microbial Pathogenesis 2017, 109, 228-232.

7. BN Patil and TC Taranath. Limonia acidissima L. leaf mediated synthesis of silver and zinc oxide nanoparticles and their antibacterial activities. Microbial Pathogenesis 2018, 115, 227-232. 8. R Kirubha and G Alagumuthu. Production of biogenic silver nanoparticles using Ziziphus jujuba fruit extract. Int. J. Pharm. Res. Bio-Sc. 2014, 3(5), 287-297.

9. BS Maria, A Devadiga, VS Kodialbail and MB Saidutta. Synthesis of silver nanoparticles using medicinal Zizyphus xylopyrus bark extract. Appl. Nanosci. 2015, 5, 755-762. 
10. MA Abdel-Fatah, NH Hussein, SI Hawash and HH Shaarawy. Investigation of using Sidr leave extracts in nano-silver preparation. ARPN J. Eng. Appl. Sci. 2016, 11(19), 11649-11654.

11. L Divband, M Behzad, SB Nasab and S Divband. Investigation of nano particles efficiency prepared from Cedar fly ash (Zizyphus spinachristi) for lead $\left(\mathrm{Pb}^{+2}\right)$ removal from aqueous solution. Iranian J. Health Environ. 2012, 5(2), 65.

12. JD Neama, NMJ Abu-Mejdad and AM Jaber. Evaluation the antimicrobial activity of aqueous and alcoholic extracts of leaves Ziziphus spina-christi (L) Desf. Basrah J. Sci B 2007, 25(1), $1-16$.

13. HI Abd Al-Wahab and TA Hussien. Study the effect of aqueous cold water and alcoholic extracts of Ziziphus spina christi against bacteria isolated from conjunctivitis in vitro and in vivo. Baghdad Sci. J. 2015, 12(1), 14-19.

14. RA-M Saqur, WJ Atia and YK Abbas. The study of some chemical components of vegetative parts of Jujube Ziziphus spina-christi L. Wild. var. spina-christi and Banber Cordia myxa L. plants. J. Thi-Qar Sci. 2014, 4(2), 112-120.

15. HM Kredy. Antibacterial activity of saponins extract from Sider (Ziziphus spina_christi). J. Thi-Qar Univ. 2010, 6(1), 16.

16. A Michel. Tree, Shrub and Liana of West African Zone, Margraf Publishers GMBH, Paris. 2002, p. 440 .

17. JA Duke and ES Ayensu. Medicinal plants of China, Reference Publication Inc., 1985, 20, p.4

18. DK Cherry, E Hing and DA Woodwell. National Ambulatory Medical Care Survey: 2006 Summary Number 3. August 6, 2008.

19. MN Owaid and IJ Ibraheem. Mycosynthesis of nanoparticles using edible and medicinal mushrooms. Eur. J. Nanomed. 2017, 9(1), 5-23.

20. MN Owaid, SSS Al Saeedi and IA Abed. Study on UV-visible for detection of biosynthesis of silver nanoparticles by oyster mushroom's extracts. J. Water Environ. Nanotech. 2017, 2(1), $66-70$

21. R Bhat, VG Sharanabasava, R Deshpande, U Shetti, G Sanjeev and A Venkataraman. Photobio-synthesis of irregular shaped functionalized gold nanoparticles using edible mushroom Pleurotus florida and its anticancer evaluation. J. Photochem. Photobio. B: Bio. 2013, 125, 63-69. 22. B Sadeghi. Zizyphus mauritiana extract-mediated green and rapid synthesis of gold nanoparticles and its antibacterial activity. J. Nanostruct. Chem. 2015, 5, 265-273.

23. T Hamouda, A Myc, B Donovan, A Shih, JD Reuter and JR Baker. A novel surfactant nanoemulsion with a unique non-irritant topical antimicrobial activity against bacteria, enveloped viruses and fungi. Microbiol Res. 200o, 156, 1-7.

24. P Dibrov, J Dzioba and KK Gosink. Chemiosmotic mechanism of antimicrobial activity of $\mathrm{Ag}(+)$ in Vibrio cholerae. Antimicrob Agents Chemother 2002, 46, 2668-2670.

25. MN Owaid, J Raman, H Lakshmanan, SSS Al-Saeedi, V Sabaratnam and IAA Al-Assaffii. Mycosynthesis of silver nanoparticles from Pleurotus cornucopiae var. citrinopileatus and its inhibitory effects against Candida sp. Mater. Lett. 2015, 153, 186-190.

26. S Prabhu and EK Poulose. Silver nanoparticles: mechanism of antimicrobial action, synthesis, medical applications, and toxicity effects. Int. Nano Lett. 2012, 2, 1-10.

\section{A new spectrophotometric method for the determination of gabapentin using chromotropic acid}

Olayemi M. Adegbolagun ${ }^{1}$, Olusegun E. Thomas ${ }^{1}$, Elizabeth 0 . Aiyenale ${ }^{1}$, Olajire A. Adegoke ${ }^{1 *}$

1 University of Ibadan, Faculty of Pharmacy, Department of Pharmaceutical Chemistry, Ibadan, Nigeria.

\section{ABSTRACT}

The purpose was to develop a colorimetric method for determining gabapentin.

The method was based on the diazo coupling reaction between diazotized gabapentin and chromotropic acid. The method was validated using ICH guidelines before its application to generic brands of gabapentin.

Coupling reaction generated an orange azo adduct whose absorbance was linearly correlated with concentration in the range of $1-6 \mu \mathrm{g} / \mathrm{mL}$ at $470 \mathrm{~nm}$. The method was accurate and precise with recovery range of 97.6-103.1\%; intra- and inter-day precisions (\%RSD) were less than $0.65 \%$ and showed no statistical difference when compared with reference method in the analysis of the dosage forms. The $3 \mathrm{D}$ optimization of the adduct revealed an E-type configuration around the azo linkage which would contribute to its stability.

The new method can serve as a reliable alternative to the official method for the routine analysis of gabapentin in bulk and dosage forms.

Keywords: Gabapentin, colorimetric analysis, chromotropic acid, diazo coupling reaction.

\section{INTRODUCTION}

Epilepsy is a neurological disorder that is associated with a deficiency in gamma-aminobutyric acid (GABA) receptors in the microgyric cortex of the brain ${ }^{1}$ With an estimated 4 to 10 persons per 1000 people in the general population with active epilepsy i.e. continuing seizures or need for treatment, epilepsy is the fourth most common neurological disorder after migraine, stroke and Alzheimer's disease ${ }^{2,3}$. Of this world-wide incidence, $80 \%$ of those with the disorder live in low- and middle-income countries where the incidence is prob-

'Corresponding author: 0 lairr A Adegoke, e-mail: ao adegoke@mailuiedu n

(Received 22 May 2018, accepted 08 June 2018) 